\title{
Total staphylococci as performance surrogate for greywater treatment
}

\author{
David C. Shoults ${ }^{1} \cdot$ Nicholas J. Ashbolt ${ }^{1}$
}

Received: 25 August 2016/Accepted: 18 April 2017 /Published online: 1 May 2017

(C) The Author(s) 2017. This article is an open access publication

\begin{abstract}
Faecal indicator bacteria (FIB) are commonly used as water quality indicators; implying faecal contamination and therefore the potential presence of pathogenic enteric bacteria, viruses, and protozoa. Hence in wastewater treatment, the most commonly used treatment process measures (surrogates) are total coliforms, faecal coliforms, Escherichia $\operatorname{coli}(E$. coli), and enterococci. However, greywater potentially contains skin pathogens unrelated to faecal load, and E. coli and other FIB may grow within greywater unrelated to pathogens. Overall, FIB occurs at fluctuating and relatively low concentrations compared to other endogenous greywater bacteria affecting their ability as surrogates for pathogen reduction. Therefore, unlike municipal sewage, FIB provides a very limited and unreliable log-reduction surrogate measure for on-site greywater treatment systems. Based on our recent metagenomic study of laundry greywater, skin-associated bacteria such as Staphylococcus, Corynebacterium, and Propionibacterium spp. dominate and may result in more consistent treatment surrogates than traditional FIB. Here, we investigated various Staphylococcus spp. as potential surrogates to reliably assay over 4- $\log _{10}$ reduction by the final-stage UV disinfection step commonly used for on-site greywater reuse, and compare them to various FIB/phage surrogates. A collimated UV beam was used to determine the efficacy of UV inactivation (255, 265 and $285 \mathrm{~nm}$ ) against E. coli, Enterococcus faecalis, E. faecium, E. casseliflavus, Staphylococcus aureus, and S. epidermidis. Staphylococcus spp. was estimated by combining the bi-linear
\end{abstract}

Responsible editor: Philippe Garrigues

David C. Shoults

dshoults@ualberta.ca

1 School of Public Health, University of Alberta, Room 3-57, South Academic Building, Edmonton, AB T6E 2G7, Canada dose-response curves for $S$. aureus and S. epidermidis and was shown to be less resistant to UV irradiation than the other surrogates examined. Hence, a relative inactivation credit is suggested; whereas, the doses required to achieve a 4 and $5-\log _{10}$ reduction of Staphylococcus spp. (13.0 and $20.9 \mathrm{~mJ} \mathrm{~cm}^{-2}$, respectively) were used to determine the relative inactivation of the other microorganisms investigated. The doses required to achieve a 4 and 5- $\log _{10}$ reduction of Staphylococcus spp. resulted in a $\log _{10}$ reduction of 1.4 and 4.1 for E. coli, 0.8 and 2.8 for E. faecalis, 0.8 and 3.6 for E. casseliflavus and 0.8 and 1.2 for MS2 coliphage, respectively. Given the concentration difference of Staphylococcus spp. and FIB (3 to 5- $\log _{10}$ higher), we propose the use of Staphylococcus spp. as a novel endogenous performance surrogate to demonstrate greywater treatment performance given its relatively high and consistent concentration and therefore ability to demonstrate over $5-\log _{10}$ reductions.

Keywords Greywater · Graywater · Staphylococcus . Staphylococci · Water treatment · Indicator organisms · Surrogates $\cdot \mathrm{UV}$ disinfection $\cdot$ Collimated beam

\section{Introduction}

Available freshwater is an increasingly scarce commodity for many rapidly urbanizing regions, even within developed countries (World Health Organization 2016). However, increasing population growth in relatively water-scarce regions along with an increase in personal water consumption have greatly contributed to the urban water deficit faced around the world (Schiermeier 2014). There is also a greater awareness in the water-energy nexus (Sathe 2013), and that most household water use does not need to be treated to drinking water quality. In particular, many circumpolar communities lack adequate 
quantities of water for potable and non-potable purposes (Daley et al. 2014; Hennessy and Bressler 2016). Hence, one option to provide more sustainable water services is to utilize treated greywater (Schoen et al. 2014). Greywater (graywater), which can be defined as domestic household wastewater without input from the toilet (Ottosson 2003), is a valuable commodity which should be utilized to reduce water usage. In-home greywater reuse is not widely practiced, and is illegal to reuse within homes throughout the majority of North America (National Research Council of the National Academics 2016), where there are many circumpolar communities still lacking sustainable water and sanitation (Thomas et al. 2016; Daley et al. 2015).

Current available technologies are capable of effectively treating greywater to potable quality; however, the cost of such systems is high (Cobacho et al. 2012) and not necessary for uses such as toilet flushing and clothes washing. There is a need for a cost effective and robust greywater treatment system that can handle the variability of contaminant composition within greywater and produce safe, disinfected, non-potable water for household uses ranging from toilet flushing to laundry, and potentially semi-continuous recirculation of shower water. Additionally, there is a need for regulatory guidelines to be designed for in-home greywater reuse including identifying adequate performance surrogates for greywater treatment processes to assess required pathogen log-reductions in riskbased guidelines (e.g. Sharvelle et al. 2017). Depending on the end use of the treated greywater, necessary $\log _{10}$ reductions may range from 5 to 13 for viruses, 4 to 9 for Cryptosporidium, 3 to 8 for Giardia, and 3 to 8 for bacteria (Schoen et al. 2017). Given complexities/costs in undertaking controlled spiking studies (Zimmerman et al. 2016), here we present the potential for using endogenous Staphylococcus spp. (total staphylococci) as a greywater treatment performance surrogate, demonstrated for ultraviolet (UV) irradiation performance testing.

\section{Ultraviolet irradiation}

Disinfection is an essential process in water treatment to remove/inactivate pathogenic organisms. UV inactivation is a commonly used disinfection treatment method in both wastewater and drinking water treatment, which directly damages the nucleic acids of microorganisms and inhibits future replication (Gross et al. 2015). UV is an attractive disinfection method and considered to be a more environmentally friendly disinfection technology than chemical disinfection (Winward et al. 2008). Additionally, UV is often preferred over chlorine because the use of chlorine may leave residual chlorine compounds that may have adverse effects, such as generating odorous substances and biohazardous disinfection byproducts (Chang et al. 1985; Mori et al. 2007). However, UV irradiation does have its limitations; Winward et al.
(2008) showed raw greywater having higher turbidity, larger mean particle size, lower $\mathrm{UV}_{254}$ transmittance, and higher total suspended solids' (TSS) levels relative to raw municipal wastewater. This can be explained by the lack of dilution of greywater when compared to municipal wastewater. Winward et al. (2008) also showed that the presence of larger particles in greywater limited the effectiveness of UV irradiation, causing an extreme tailing effect of coliforms reduction even in with UV doses up to $239 \mathrm{~mJ} \mathrm{~cm}^{-2}$. Hence, for UV irradiation to be an effective pathogen reduction step in greywater treatment, adequate pre-treatment must be performed to ensure adequate $\mathrm{UV}_{254}$ transmissivity and removal of larger particles capable of shielding microorganisms.

\section{Process indicators, faecal indicators and index organisms}

There is often confusion between the semantics and purposes of process indicators (surrogates), faecal indicators, and pathogen index organisms. It is important to make a distinction between the use of indicators generally and surrogates specifically, as the roles of such are not necessarily interchangeable. Table 1 exhibits the key differences between the three.

Process indicators (surrogates) and faecal indicator bacteria (FIB) are commonly used as indicators in water treatment to determine the potential presence of enteric viruses, bacteria and parasitic protozoan pathogens that maybe associated with faecal contamination (U.S. EPA 2012). The most commonly tested indicators are total coliforms, faecal coliforms, Escherichia coli (E. coli), and enterococci (U.S. EPA 2012). However, most greywater treatment studies inappropriately utilize FIB as an indicator of pathogen risk (Ottosson and Stenström 2003). Determining the microbiological contamination in greywater can be difficult; each source of greywater presents different potential biological contaminants and concentrations (Birks and Hills 2007). Zimmerman et al. (2014) investigated the 16S rRNA gene diversity of laundry water and identified skin-associated bacterial members of Staphylococcus, Corynebacterium, and Propionibacterium as the major members of that microbiome. Using quantitative polymerase chain reaction (qPCR) they showed that in the university gym laundry samples taken, Staphylococcus spp. averaged from 3 to 5 orders of magnitude higher than faecal source markers including total Bacteroides spp., human-specific Bacteroides, Enterococcus spp., and $E$. coli, in ascending orders of magnitude, respectively (Zimmerman et al. 2014). Due to the direct contact of clothing with human skin and the prevalence of the opportunistic pathogen Staphylococcus aureus (S. aureus) on the human body (Zimmerman et al. 2014), S. aureus may be at concentrations up to $5 \times 10^{5}$ cfu. $100 \mathrm{~mL}^{-1}$ (Burrows et al. 1991; Nolde 1999; Gilboa and Friedler 2008), but as with any pathogen, is not always present. Hence, $S$. aureus, enteric pathogens and FIB are present in varying and often low concentrations in greywater, with some of the FIB exhibiting growth within greywater 
Table 1 Definitions for indicator and index microorganisms of public health concern (World Health Organization 2001, 2016)

Group
Process indicator (surrogate)

Process indicator (surrogate)

Faecal indicator

Index and model organisms

\section{Definition}

A group or organism that demonstrates the efficacy of a process, such as total heterotrophic bacteria or total coliforms for chlorine disinfection.

A group or organism that indicates the presence of faecal contamination, such as the bacterial groups thermotolerant coliforms or E. coli. Hence, they only infer that pathogens may be present.

A group/or species indicative of pathogen presence and behaviour respectively, such as E. coli as an index for Salmonella presence and F-RNA coliphages as models of human enteric virus behaviour. systems (e.g. E. coli) (Ottosson and Stenström 2003). If regrowth occurs (either in the raw greywater holding tank or after treatment as reported by Friedler and Gilboa (2010), it is problematic to quantify the reduction occurring across any treatment step. Furthermore, traditional indicator organisms used in North America are not adequate surrogates to represent the logreductions likely required to produce safe greywater (Sharvelle et al. 2017; Gilboa and Friedler 2008). Hence, the focus of this paper is to determine if endemic greywater staphylococci, including pathogens such as $S$. aureus, may be suitable treatment surrogates to reliably assay over 4- $\log _{10}$ reductions of key pathogens (Birks and Hills 2007; Zimmerman et al. 2014; Fogarty et al. 2015; Gross et al. 2007) by UV disinfection.

\section{Ultraviolet irradiation of staphylococci}

Commercial UV systems generally deliver $254 \mathrm{~nm}$ UV-C from mercury-vapour lamps that impact on nucleic acid within microorganisms; however some manufacturers also use polychromatic UV-C lamps (including higher wavelength UV-C) that also impact on cellular proteins (Eischeid and Linden 2011). Little is known as to the efficacy of UV inactivation towards staphylococci, and in particular the pathogenic species $S$. aureus (Benami et al. 2013). Overall, there is a collective need for actionspectra and dose-response curves describing UV inactivation of $S$. aureus, as well as other Staphylococcus spp. generally and within greywater. Furthermore, given the above listed limitations with FIBs as process indicators for the removal of pathogens in greywater reuse, knowledge on the efficacy of UV inactivation towards staphylococci may provide future options for risk management monitoring. Most limiting is a lack of knowledge on the fate of pathogens (both enteric and saprozoic) via different greywater treatment systems, (Ashbolt 2015) and if demonstrated of value for enteric bacteria performance, total staphylococci may also provide value to address these additional pathogen concerns.

\section{Materials and methods}

\section{Bacterial culturing, plating and enumeration}

Freeze dried S. aureus (ATCC 25923), Staphylococcus epidermidis (S. epidermidis) (ATCC 12228), Escherichia coli (E. coli) (ATCC 13115), E. coli* (ATCC 15597), Enterococcus faecalis (E. faecalis) (ATCC 29212), and Enterococcus casseliflavus (E. casseliflavus) (ATCC 9199) were purchased from American Type Culture Collection (ATCC) and revived according to ATCC protocols. ATCC bacteria culture stocks were stored at $-80^{\circ} \mathrm{C}$ in a cryomedium to glycerol ratio of $3: 2$. When needed, bacteria cultures were inoculated into the brain hearth infusion (BHI) liquid media and incubated at $37^{\circ} \mathrm{C}$.

\section{Phage culturing, plating and enumeration}

Aliquots $(200 \mu \mathrm{L})$ of the F-RNA coliphages MS2 (ATCC 15597-B1) were used to infect E. coli* while in its exponential phase during incubation as described in Method 1601 (U.S. EPA 2001). Briefly, after $18 \mathrm{~h}$ of growth and infection time, the sample was filtered through a $0.22 \mu \mathrm{m}$ filter to recover the coliphages and plaque within a semi-soft tryptic soy agar (TSA) overlay containing $0.7 \%$ agar. Plates were then incubated at $37^{\circ} \mathrm{C}$ for $24 \mathrm{~h}$ before counting plaque-forming units (PFUs).

\section{UV irradiation}

Liquid medium containing the test organism was diluted to 1:100 (for bacteria) and 1:1000 (for MS2 coliphage) in sterile deionized (DI) water inside a $60 \mathrm{~mm}$ Petri plate containing a $5 \mathrm{~mm} \times 2 \mathrm{~mm}$ stir bar which was then placed on a magnetic stirrer at $400 \mathrm{rpm}$ to facilitate mixing without a vortex forming. DI water was used rather than tap water in order to minimize potential contact with residual chlorine, which could have an inactivation effect on the cells (Zyara et al. 2016). 
Controls with bacteria suspended in sterile DI water were performed to investigate any loss in viability due to osmotic pressure change. No significant difference in $\log _{10} \mathrm{CFU}$ count was observed from $100 \mathrm{~s}$ after pipetting from the BHI liquid media (the time needed to dilute the cells to a countable dilution) to $20 \mathrm{~min}$ (the estimated maximum time cells might be suspended in DI water throughout the experiment). Prior to exposing the sample to the UV, a $100-\mu \mathrm{L}$ sample was pipetted out of the mixed solution and diluted to the appropriate dilution before being plated in triplicate. The collimated beam was then placed over the sample and the desired wavelength dose was delivered to the sample.

Based on an initial experiment performed for each test organism to determine the approximate dose needed for a 4$\log _{10}$ reduction, a second experiment was performed to estimate an 11-point dose-response curve. Samples were taken at $0,15,30,45,60,75,90,105,120,135$, and $150 \%$ of the dose calculated for an estimated $4-\log _{10}$ reduction. Subsamples $(100 \mu \mathrm{L})$ were taken at appropriate times, diluted in DI water, and plated to determine the $\log _{10}$ reduction at each dosage using the following equation:

$\log _{10}$ Reduction $=\log \left(\frac{\frac{C F U \text { Control }}{100 m L}}{\frac{C F U \text { Dosage }}{100 m L}}\right)$

An AquaSense Pearl Beam collimated UV reactor (Florence, KY USA) was used to deliver 255, 265, or $285 \mathrm{~nm}$ UV-C irradiation to test organisms suspended in water using a modified EPA protocol (U.S. EPA 2006). Equation 2 was used to calculate the effective intensity $\left(E_{\text {ave }}\right)$ of the collimated beam based on measurable variables: (NSF International 2014)

$E_{\text {ave }}=0.98\left[\frac{E_{0}}{L}\left(\frac{(1-A)^{L}-1}{\ln (1-A)}\right)\right]$

The incident intensity $\left(E_{0}\right)$ was measured using a NSF certified radiometer calibrated for the three test wavelengths (UVP radiometer, model UVX-25). The water height $(L)$ was measured to $1 \mathrm{~cm}(28.3 \mathrm{~mL}$ in a $60-\mathrm{mm}$ cylindrical Petri dish), and a spectrophometer (Thermo Scientific GENESYS 10S UV-VIS) was used to measure the absorbance (A) of $255 \mathrm{~nm}$ UV by the suspending medium. The resulting $E_{\text {ave }}$ was then multiplied by the exposure time (seconds) in order to calculate the resulting dosage measured in $\mathrm{mJ} \mathrm{cm}^{-2}$.

\section{Results}

Data points from each experiment were plotted to display the dose-response of each organism relative to $255 \mathrm{~nm}$ UV irradiation. Figure 1 shows the relative dose-response to UV by S. aureus, S. epidermidis, E. faecalis, E. casseliflavus, E. coli, and MS2 coliphage.

S. aureus and S. epidermidis are generally the most common Staphylococcus spp. colonizing humans, (Coates et al. 2014) and therefore were used in order to represent total staphylococci in the bench experiments to determine the efficacy of UV inactivation. Data points for the $S$. epidermidis decay curve were interpolated to estimate $\log _{10}$ reduction values for the dosages for each $S$. aureus point. A weighted average was then taken of each point to estimate a dose-response curve for Staphylococcus spp., which is shown in Fig. 2. Figure 2 also depicts the bi-linear decay curve with total staphylococci; two trend lines were plotted to determine the decay equation (in units of $\log _{10}$ Reduction (LR) per $\mathrm{mJ} \mathrm{cm}^{-2}$ ) in the bi-linear graph to determine the decay coefficients $\mathrm{K}_{1}(0.435$ LR per $\left.\mathrm{mJ} \mathrm{cm}^{-2}\right)$ and $\mathrm{K}_{2}\left(0.1283 \mathrm{LR}\right.$ per $\left.\mathrm{mJ} \mathrm{cm}^{-2}\right)$. These equations, along with the decay equations and respective $R^{2}$ values for the other test organisms are shown in Table 2. These equations were used to determine the relative reduction for each organism compared to total staphylococci.

\section{Comparison of 255, 265, and $285 \mathrm{~nm} \mathrm{UV}$ on $S$. aureus inactivation}

Also explored was a comparative evaluation of 255, 265, and $285 \mathrm{~nm}$ UV irradiation on $S$. aureus to determine the most
Fig. 1 Comparison of inactivation of Staphylococcus spp., FIB and MS2 coliphage by $255 \mathrm{~nm}$ UV (average log reduction values $\pm \mathrm{SD}$ )

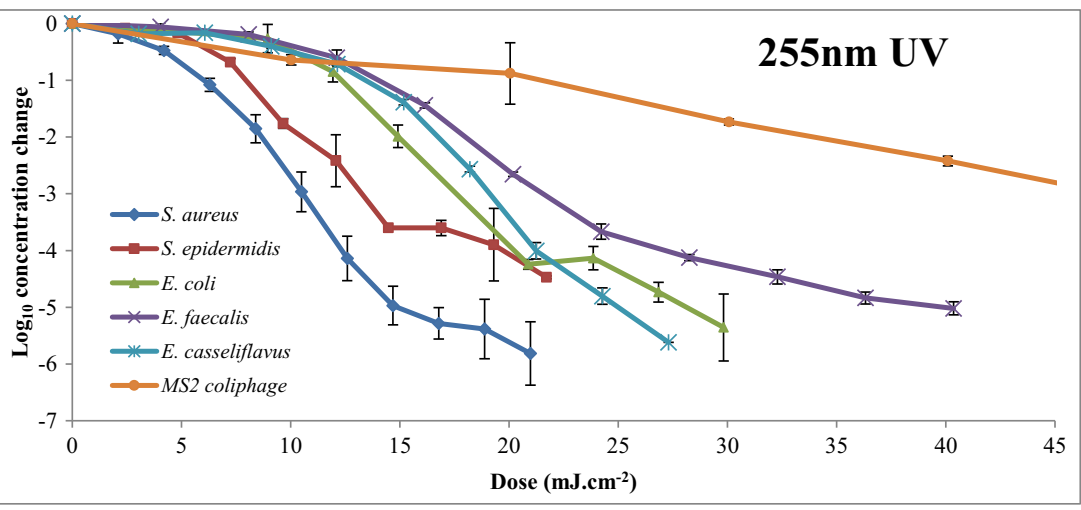


Fig. 2 Bi-linear box and whisker plot for UV (255 nm) decay curve of total staphylococci (average of S. aureus and S. epidermidis)

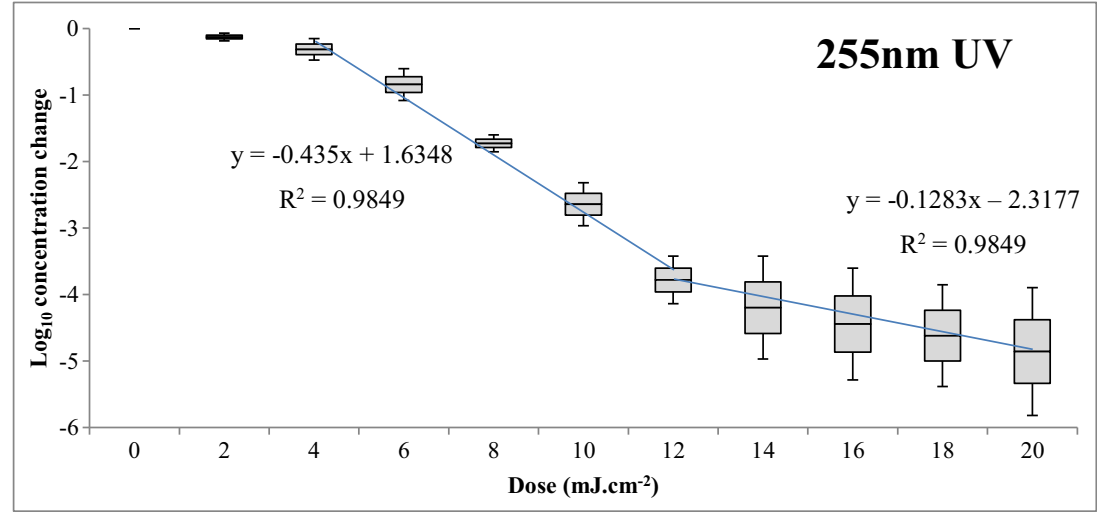

effective wavelength for inactivation. The initial experiment for $285 \mathrm{~nm}$ yielded very little inactivation and was not explored any further. The $255 \mathrm{~nm}\left(11.8 \mathrm{~mJ} \mathrm{~cm}^{-2}\right.$ for $4-\log _{10}$ reduction) UV wavelength was observed to be more effective in inactivating $S$. aureus than $265 \mathrm{~nm}\left(17.1 \mathrm{~mJ} \mathrm{~cm}^{-2}\right.$ for a 4$\log _{10}$ reduction).

\section{Discussion}

Previously published data on FIB identified them as poor performance surrogates for greywater treatment (Ottosson and Stenström 2003; Birks and Hills 2007; Zimmerman et al. 2014). Key criteria for a suitable performance surrogate are given in Table 3, which compares FIB and Staphylococcus spp. Traditional FIB failed to satisfy the first three criteria, due to their inconsistent presence with varying, and generally low concentration (Ottosson and Stenström 2003; Zimmerman et al. 2014) and lack of correlation with pathogen presence; (Birks and Hills 2007) this is enough to determine that traditional FIB are not suitable performance surrogates for grey-water treatment. In contrast, total staphylococci meet the first three criteria due to their consistent and high concentration in

Table $2255 \mathrm{~nm}$ UV-C decay curves for various organisms (linear equations represent the line of best fit for the linear segments of each decay curve)

\begin{tabular}{lll}
\hline Organism & Linear equation $\left(\mathrm{x}\right.$ units: $\left.\left[\mathrm{mJ} \mathrm{cm}^{-2}\right]\right)$ & $R^{2}$ \\
\hline Staphylococcus spp. & $\mathrm{y}=-0.435 \mathrm{x}+1.6348(\mathrm{x}<12)$ & 0.9849 \\
& $\mathrm{y}=-0.1283 \mathrm{x}-2.3177(12<\mathrm{x}<20)$ & 0.973 \\
E. coli & $\mathrm{y}=-0.343 \mathrm{x}+3.0246(9<\mathrm{x}<21)$ & 0.9873 \\
& $\mathrm{y}=-0.132 \mathrm{x}+1.2697(21<30)$ & 0.8306 \\
E. faecalis & $\mathrm{y}=-0.258 \mathrm{x}+2.5954(12<\mathrm{x}<24)$ & 0.9956 \\
& $\mathrm{y}=-0.0847 \mathrm{x}-1.6868(24<\mathrm{x}<40)$ & 0.9818 \\
E. casseliflavus & $\mathrm{y}=-0.3527 \mathrm{x}+3.8164(14<\mathrm{x}<25)$ & 0.9849 \\
MS2 coliphage & $\mathrm{y}=-0.0607 \mathrm{x}+0.0323(0<\mathrm{x}<90)$ & 0.9916 \\
\hline
\end{tabular}

greywater; (Zimmerman et al. 2014; Burrows et al. 1991; Nolde 1999; Gilboa and Friedler 2008) presumably, due to the high presence of staphylococci colonizing human skin (Coates et al. 2014) and the correlation of presence when human mitochondrial DNA (HmtDNA) is detected in greywater (Zimmerman et al. 2014). It is important to acknowledge that although some studies showed a non-detect of $S$. aureus in raw greywater samples (Casanova et al. 2001; Siegrist 1977) this is no surprise for a pathogen (as we are not always infected); whereas, other skin staphylococci are likely to be present. For example, Zimmerman et al. (2014) reported $S$. aureus at approximately $5-\log _{10}$ lower concentration than Staphylococcus spp. in laundry greywater. In addition, approximately $30-40 \%$ of humans carry $S$. aureus (Kluytmans et al. 1997; Cole et al. 2001), while Staphylococcus spp. has been shown to dominate the microbiota of approximately $60 \%$ of humans (Callewaert et al. 2013). The fourth criteria explored, stating that an appropriate performance surrogate must have greater survival than target pathogens is still in question. More research is needed to determine the spectrum of genera present within a variety of greywater sources, and their treatment requirements for a 3.5 to $6-\log _{10}$ removal, as likely needed for different domestic greywater reuse (Sharvelle et al. 2017). Although Staphylococcus spp. showed less resilience to UV than the FIB bacteria tested

Table 3 Comparison of FIB and Staphylococcus spp.

\begin{tabular}{lll}
\hline Criteria & FIB & $\begin{array}{l}\text { Staphylococcus } \\
\text { spp. }\end{array}$ \\
\hline Consistent presence & × & $\checkmark$ \\
$\begin{array}{l}\text { Higher concentration than target pathogens } \\
\begin{array}{l}\text { Identifiable correlation to presence of target } \\
\text { pathogens }\end{array}\end{array}$ & × & $\checkmark$ \\
$\begin{array}{l}\text { Same or greater survival as target pathogens } \\
\text { ?am }\end{array}$ & $?$ \\
\hline
\end{tabular}


in the collimated UV beam bench test, total staphylococci are expected to be a minimum of $3-\log _{10}$ higher in concentration than the FIB traditionally used. Due to the high and consistent concentrations of Staphylococcus spp., we are suggesting inactivation curves for each reference pathogen can be used to determine $\log _{10}$ reductions relative to Staphylococcus spp. (World Health Organization 2016).

Since total staphylococci were observed to be more susceptible to inactivation by UV irradiation than FIB, Staphylococcus spp. inactivation cannot be used as enteric pathogen surrogates, such as E. coli, enterococci, and MS2 coliphage. In order to gauge the relative $\log _{10}$ reduction between Staphylococcus spp. and the other organisms which were tested, the linear equations for each organism was used to estimate the $\log _{10}$ reduction that would be observed relative to the dosage required for a 4 and 5$\log _{10}$ reduction for Staphylococcus spp., respectively: being 13.0 and $20.9 \mathrm{~mJ} \mathrm{~cm}^{-2}$, respectively. These dosages were then used in the linear equations obtained from each decay curve (displayed in Table 2) to determine their relative $\log _{10}$ reduction to Staphylococcus spp. (Table 4).

Given the high concentrations of Staphylococcus spp. present in greywater, relative to FIB (ranging from 3 to 5$\log _{10}$ higher) (Zimmerman et al. 2014), total staphylococci may still serve as a conservative measure for pathogen reduction for enteric bacteria, especially at the dosage for an observed 5- $\log _{10}$ reduction of Staphylococcus spp.; the $\log _{10}$ reduction difference at $20.9 \mathrm{~mJ} \mathrm{~cm}^{-2}$ observed between Staphylococcus spp. and the enteric bacteria tested is less than $3-\log _{10}$, which is satisfactory given the 3 to 5 $\log _{10}$ concentration difference reported by Zimmerman et al. (2014). However, the UV dosage required to achieve a $5-\log _{10}$ reduction of Staphylococcus spp. is estimated to only achieve some $1.2-\log _{10}$ reduction in MS2 coliphage; this suggests Staphylococcus spp. would likely not be an adequate surrogate for enteric virus reduction in greywater, and an additional surrogate, such as endogenous (staphylococci) bacteriophages, is needed to represent enteric virus reduction.

Table $4 \log _{10}$ reduction credits relative to 4 and $5-\log _{10}$ reduction of Staphylococcus spp.

\begin{tabular}{lll}
\hline Organism & $\begin{array}{l}\log _{10} \text { reduction } \\
\text { observed at } \\
13.0 \mathrm{~mJ} \mathrm{~cm}^{-2}\end{array}$ & $\begin{array}{l}\log _{10} \text { reduction } \\
\text { observed at } \\
20.9 \\
\mathrm{~mJ} \mathrm{~cm}^{-2}\end{array}$ \\
\hline Staphylococcus spp. & 4 & 5 \\
E. coli & 1.4 & 4.1 \\
E. faecalis & 0.8 & 2.8 \\
E. casseliflavus & 0.8 & 3.6 \\
MS2 coliphage & 0.8 & 1.2 \\
\hline
\end{tabular}

Acknowledgements The authors are most grateful for project funding from Alberta Innovates - Health Solutions, including MSc student stipends support, along with travel support from the Norwegian Ministry of Foreign Affairs (MFA) and administered by the Norwegian Centre for International Cooperation in Education (SIU) via the joint project (NorCan) with Petter Jenssen of the Norwegian University of Life Sciences that enabled presentation of some aspects of this work at ARTEK, Technical University of Denmark, April 12, 2016 Sisimiut, Greenland.

Open Access This article is distributed under the terms of the Creative Commons Attribution 4.0 International License (http:// creativecommons.org/licenses/by/4.0/), which permits unrestricted use, distribution, and reproduction in any medium, provided you give appropriate credit to the original author(s) and the source, provide a link to the Creative Commons license, and indicate if changes were made.

\section{References}

Ashbolt NJ (2015) Environmental (saprozoic) pathogens of engineered water systems: understanding their ecology for risk assessment and management. Pathogens 4(2):390-405

Benami M, Gross A, Herzberg M, Orlofsky E, Vonshak A, Gillor O (2013) Assessment of pathogenic bacteria in treated graywater and irrigated soils. Sci Total Environ 458-460:298-302

Birks R, Hills S (2007) Characterisation of indicator organisms and pathogens in domestic greywater for recycling. Environ Monit Assess 129(1-3):61-69

Burrows WD, Schmidt MO, Carnevale RM, Schaub SA (1991) Nonpotable reuse: development of health criteria and technologies for shower water recycle. Wat Sci Technol 24(9):81-88

Callewaert C, Kerckhof FM, Granitsiotis MS, Van Gele M, Van de Wiele T, Boon N (2013) Characterization of Staphylococcus and Corynebacterium clusters in the human axillary region. PLoS One 8(8):e70538

Casanova LM, Gerba CP, Karpiscak M (2001) Chemical and microbial characterization of household graywater. Environ Sci Health A36(4):395-401

Chang JCH, Ossoff SF, Lobe DC, Dorfman MH, Dumais CM, Qualls RG, Johnson JD (1985) UV inactivation of pathogenic and indicator microorganisms. Appl Environ Microbiol 49(6):1361-1365

Coates R, Moran J, Horsburgh MJ (2014) Staphylococci: colonizers and pathogens of human skin. Future Microbiol 9(1):75-91

Cobacho R, Martín M, Palmero C, Cabrera E (2012) Key points in the practical implementation of greywater recycling systems. The Spanish situation in the global context. Water Science \& Technology: Water Supply 12(3):406

Cole AM, Tahk S, Oren A, Yoshioka D, Kim YH, Park A, Ganz T (2001) Determinants of Staphylococcus aureus nasal carriage. Clin Diagn Lab Immunol 8(6):1064-1069

Daley K, Castleden H, Jamieson R, Furgal C, Ell L (2014) Municipal water quantities and health in Nunavut households: an exploratory case study in coral harbour, Nunavut, Canada. Int J Circumpolar Health 73:1-10

Daley K, Castleden H, Jamieson R, Furgal C, Ell L (2015) Water systems, sanitation, and public health risks in remote communities: inuit resident perspectives from the Canadian Arctic. Soc Sci Med 135:124 132

Eischeid AC, Linden KG (2011) Molecular indications of protein damage in adenoviruses after UV disinfection. Appl Environ Microbiol 77(3):1145-1147

Fogarty, L. R.; Haack, S. K.; Johnson, H. E.; Brennan, A. K.; Isaacs, N. M.; Spencer, C., Staphylococcus aureus and methicillin-resistant 
S. aureus (MRSA) at ambient freshwater beaches. J Water Health 2015, 13 (3), 680-692.

Friedler E, Gilboa Y (2010) Performance of UV disinfection and the microbial quality of greywater effluent along a reuse system for toilet flushing. Sci Total Environ 408(9):2109-2117

Gilboa Y, Friedler E (2008) UV disinfection of RBC-treated light greywater effluent: kinetics, survival and regrowth of selected microorganisms. Water Res 42(4-5):1043-1050

Gross A, Kaplan D, Baker K (2007) Removal of chemical and microbiological contaminants from domestic greywater using a recycled vertical flow bioreactor (RVFB). Ecol Eng 31(2):107-114

Gross A, Stangl F, Hoenes K, Sift M, Hessling M (2015) Improved drinking water disinfection with UVC-LEDs for Escherichia coli and Bacillus subtilis utilizing quartz tubes as light guide. Water 7(9):4605-4621

Hennessy TW, Bressler JM (2016) Improving health in the Arctic region through safe and affordable access to household running water and sewer services: an Arctic Council initiative. Int J Circumpolar Health 75:31149

Kluytmans J, van Belkum A, Verbrugh H (1997) Nasal carriage of Staphylococcus aureus: epidemiology, underlying mechanisms, and associated risks. Clin Microbiol Rev 10(3):505-520

Mori M, Hamamoto A, Takahashi A, Nakano M, Wakikawa N, Tachibana S, Ikehara T, Nakaya Y, Akutagawa M, Kinouchi Y (2007) Development of a new water sterilization device with a 365 nm UV-LED. Med Biol Eng Comput 45(12):1237-1241

National Research Council of the National Academics (2016) Using graywater and stormwater to enhance local water supplies: an assessment of risks, costs, and benefits. National Research Council of the National Academics, Washington, D.C., p 420

Nolde E (1999) Greywater reuse systems for toilet flushing in multistorey buildings-over ten years experience in Berlin. Urban Water 1(4):275-284

NSF International (2014) NSF/ANSI 55-2014. In: Ultraviolet microbiological water treatment systems

Ottosson J (2003) Hygiene aspects of greywater and greywater reuse. Royal Institute of Technology (KTH), Stockholm

Ottosson J, Stenström TA (2003) Growth and reduction of microorganisms in sediments collected from a greywater treatment system. Lett Appl Microbiol 36(3):168-172

Sathe A (2013) California's sustainable future: understanding the waterenergy nexus vital to resource management. J Am Water Works Assoc 105(6):67-71

Schiermeier Q (2014) Water risk as world warms. First comprehensive global-impact project shows that water scarcity is a major worry. Nature 505:10-11
Schoen ME, Xue X, Hawkins TR, Ashbolt NJ (2014) Comparative human health risk analysis of coastal community water and waste service options. Environ Sci Technol 48(16):9728-9736

Schoen ME, Ashbolt NJ, Jahne MA, Garland J (2017) Risk-based enteric pathogen reduction targets for non-potable and direct potable use of roof runoff, stormwater, and greywater. Microbial Risk Analysis. doi:10.1016/j.mran.2017.01.002

Sharvelle S., Ashbolt N., Clerico E., Hultquist R., Leverenz H., Olivieri A. (2017) Risk based approach for the development of public health standards for decentralized nonpotable water systems (DNWS); WERF Project SIWM10C15 via National Water Reuse Institute (NWRI), Water Environment Research Foundation

Siegrist RL (1977) Waste segregation to facilitate onsite wastewater disposal alternatives. University of Wisconsin, Madison

Thomas TK, Ritter T, Bruden D, Bruce M, Byrd K, Goldberger R, Dobson J, Hickel K, Smith J, Hennessy T (2016) Impact of providing in-home water service on the rates of infectious diseases: results from four communities in Western Alaska. J Water Health 14(1): $132-141$

U.S. EPA (2001) Method 1601: male-specific (F+) and somatic coliphage in water by two-step enrichment procedure. Office of Water, United States Environmental Protection Agency, Washington, D.C.

U.S. EPA (2006) Ultraviolet disinfection guidance manual for the final long term 2 enhanced surface water treatment rule. Washington, DC USEPA, 2006; Vol. EPA 815-R-06-007.

U.S. EPA (2012) Water: monitoring \& assessment. http://water.epa.gov/ type/rsl/monitoring/vms511.cfm (Accessed 9 Nov 2016)

Winward GP, Avery LM, Stephenson T, Jefferson B (2008) Ultraviolet (UV) disinfection of grey water: particle size effects. Environ Technol 29(2):235-244

World Health Organization (2001) Water quality: guidelines, standards and health. IWA Publishing, London

World Health Organization (2016) Quantitative microbial risk assessment: application for water safety management. World Health Organization, Geneva

Zimmerman BD, Ashbolt NJ, Garland JL, Keely S, Wendell D (2014) Human mitochondrial DNA and endogenous bacterial surrogates for risk assessment of graywater reuse. Environ Sci Technol 48(14): 7993-8002

Zimmerman BD, Korajkic A, Brinkman NE, Grimm AC, Ashbolt NJ, Garland JL (2016) A spike cocktail approach to improve microbial performance monitoring for water reuse. Water Environment Research 88(9):824-837

Zyara AM, Torvinen E, Veijalainen AM, Heinonen-Tanski H (2016) The effect of chlorine and combined chlorine/UV treatment on coliphages in drinking water disinfection. J Water Health 14:640-649 